\title{
Rheological Behavior of Zirconia Added Alumina Mixture
}

\author{
Siti Norazlini Abd Aziz ${ }^{1}$, Wan Saiful Sarhan Wan Saidi², Mimi Azlina Abu Bakar ${ }^{3 *}$, Muhammad Hussain Ismail ${ }^{4}$ \\ Centre of Advance Materials Research (CAMAR) \\ Faculty of Mechanical Engineering, Universiti Teknologi MARA, \\ UiTM 40450 Shah Alam, Selangor, Malaysia \\ *Corresponding author E-mail: mimi_azlina@salam.uitm.edu.my
}

\begin{abstract}
Zirconia and alumina are one of the materials that is widely used in medical industry. Zirconia Toughened Alumina (ZTA) have great properties to be apply in the ceramic injection molding such as have high hardness and high strength. The powder used in this research are alumina and zirconia while the binder to be used in this research is using $100 \%$ single based binder of palm stearin (PS). Behavior of zirconia blended alumina was investigated by rheological testing at temperature $55^{\circ} \mathrm{C}$. Two formulations were used which is $60 \%$ (alumina/zirconia) plus 40\% PS and 64\% (alumina/zirconia) plus 36\% PS. The ratio of alumina and zirconia used in this research is fixed at $(85: 15)$ for both samples. Four basic process involved which is mixing process, injection molding, thermal debinding and sintering process has been implemented to complete ceramic injection molding (CIM). Sample were performed the thermal debinding at a heating rate $0.5^{\circ} \mathrm{C} / \mathrm{min}$ up to $700^{\circ} \mathrm{C}$ and sintering at heating rate $3^{\circ} \mathrm{C} / \mathrm{min}$ for temperature $1400^{\circ} \mathrm{C}$ and $1600^{\circ} \mathrm{C}$. The hardness was tested using Rockwell hardness test for both AZ60 and AZ64 sample. Highest hardness was obtained from the sample AZ64 at the temperature $1600{ }^{\circ} \mathrm{C}$ which is $109 \mathrm{HRR}$ compare to the $1400^{\circ} \mathrm{C}$ that achieved $95.3 \mathrm{HRR}$.
\end{abstract}

Keywords: Rheological; Zirconia; Alumina; Ceramic Injection Molding; Sintering

\section{Introduction}

Dental implantation is being developed in various application in other to increase the quality of the implantation and give better characteristic for the industries. Zirconia is investigated its characteristic and properties especially in dental implantation because zirconia have received high demand due to good antibacterial response and strengthen the mechanical properties of the element. Zirconia belong to the mineral group of silicates and was discovered by the German chemist which is M.H. Klaproth in year 1789 [1].

Zirconia have a characteristic similar to the titanium that made it being use to replace the titanium in the dental implantation. Zirconia also have a strong, ductile characteristic as well as has been applied as structural material for dental bridges, crowns, insert and implant mostly because of its biocompatibility, high fracture toughness and radiopacity [2].As for the research, the material used are Alumina powder, Zirconia and single binder which is palm stearin. The rheological behavior of zirconia added alumina mixture was investigated to determine its rheological behavior and its mechanical properties through Ceramic Injection Molding (CIM).

Ceramic injection molding (CIM) is being used widely in the industry beside Metal Injection Molding (MIM). In CIM, the process such as mixing, injection molding process, thermal debinding and sintering process are convenient [3]. The green part was obtained by using the CIM in other to determine the morphology of the sample after the mechanical testing via Scanning Electron Microscopic (SEM). In earlier stage of the process CIM, feedstock need to be obtained by following the correct formulation that have been research before going up to the next stage which is injection molding process.

The feedstock was mixed using speed mixer machine and the speed of the mixing process is at the $1200 \mathrm{rpm}$. The materials need to be mixed homogenously so that it can form good sample feedstock to proceed for next stage and takes about 20 minutes mixing period. There is an issue were highlighted regarding to the previous research where the homogenous mixing process was perform with a long period of mixing about 1 to 2 hours using the brabender or internal mixer machine $[4,5]$. This is a new invention where the CIM can be performed in just 20 minutes only. The objective of the research is to study the development method of new mixing process by using dual asymmetric centrifuge technique by speed mixer. Next, to investigate the effect of single binder palm stearin towards mechanical properties of alumina sintered part. And lastly, to determine the rheological behaviour of formulating feedstock and its properties for the successful injection moulding process

Before undergo injection molding process, the feedstock was analyzed using rheological test to study the flow behavior of formulated feedstock. A feedstock that have low viscosity, low activation energy and low behavior index, $n$ has better rheological properties for effective injection molding.

The next stage is injection molding process where the temperature supply the fluidity properties to melt the feedstock so that it can be well flow through the mold to form a green part. The PS act as temporary vehicle to the feedstock to form a shape. The injection molding process was performed at very low temperature about $55^{\circ} \mathrm{C}-60^{\circ} \mathrm{C}$ using single based binder palm stearin. As reported by Aziz et al. [4] claim that the use of $100 \%$ palm stearin was promising in providing required pseudoplastic flow for injection molding. The injection molding process can be carried out at rela- 
tively low temperature in comparison with the conventional binder systems used.

The binder acts as temporary vehicle to the feedstock. Thus, if the higher temperature used it will evaporate and make the feedstock much more brittle due to lack of binder and not applicable for injection molding requirement. After finished the injection molding process, thermal debinding will take place to remove the binder from the green part so that it will not affect the mechanical testing.

Last stage before mechanical testing is sintering process. Sintering is the process to strengthen the green part in certain temperature. The temperature for sintering process in this alumina zirconia is $1400^{\circ} \mathrm{C}$ and $1600^{\circ} \mathrm{C}$. Palm stearin is a potential binder system since it is organic and natural sources and widely available in Malaysia. Therefore, low operating temperature is expected during the processing steps, particularly during mixing and injection moulding, thus promoting better economical solution towards high production scale.

\section{Method and Procedures}

There are three stages to achieve the objectives of this research and the first one is material characterization, secondly is ceramic injection molding and third stages is mechanical testing. The rheological test also will be conducted to determine the rheological behavior of the feedstock.

\subsection{Sample Characterization}

The material that used in this research are Alumina and Zirconia powder. The morphology of the material Alumina and zirconia was determined using the Scanning Electron Microscopic (SEM). The particle size of the powder also can be determined by using SEM.

\subsection{Pycnometer Density, Differential Scanning Calorimetry (DSC) and Thermogravemetric Analysis (TGA)}

The pycnometer was used in order to determine the density of the material that used in this research located at the Heat Treatment Laboratory Faculty of Mechanical Engineering. The materials that undergo the test of the pycnometer density are Zirconia, Alumina powder and Palm Stearin. The helium gas was used in the pycnometer density to determine the density of the powder so that it can be easily done to calculate the weight of the sample when it comes the mixing process at the secondary stage. The figure 1 depicted the pycnometer density.

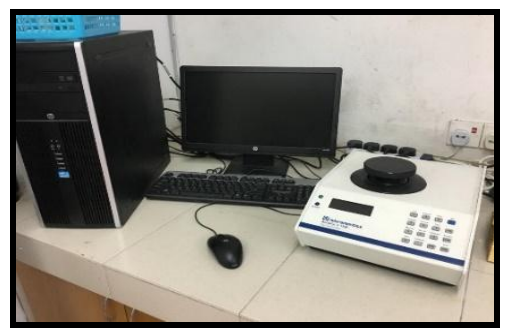

Figure 1: Pycnometer Density

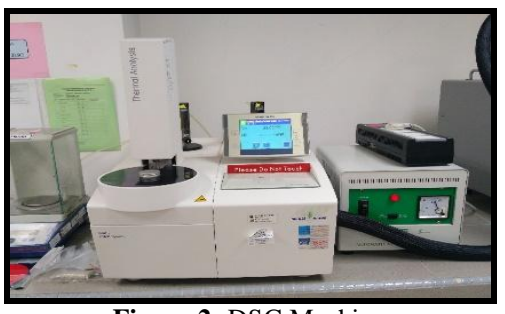

Figure 2: DSC Machine

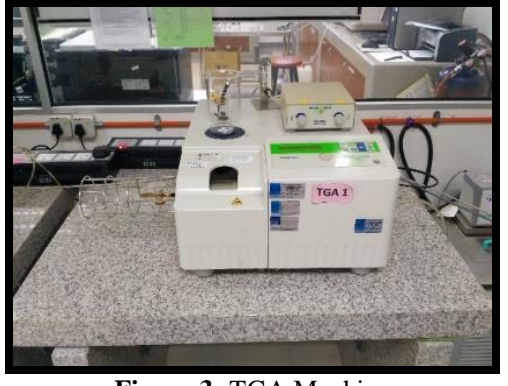

Figure 3: TGA Machine

The DSC machine was used to determine the melting point of the binder in order to proceed for the rheological behavior and through injection molding depicted in Figure 2. This is an important information where the mixing and injection molding temperature used must not above the melting point of the binder. The binder that used for this research is Palm Stearin as a single binder for this process. The DSC analysis located at the Instrumental Laboratory Faculty Chemical Engineering UITM Shah Alam.

For the test, sample must not be more than $10 \mathrm{mg}$ to run DSC analysis and the flow of the gas need to be constant rate which is $50 \mathrm{ml} / \mathrm{min}$ to avoid any failure during the process were run. The gas that use for the DSC analysis is Nitrogen gas. The heating temperature need to be set when the DSC analysis were run to test the melting point temperature of the palm stearin is $10^{\circ} \mathrm{C} / \mathrm{min}$ and will stop at the temperature $125^{\circ} \mathrm{C}$.

The Thermogravemetric Analysis (TGA) was used to determine the decomposition temperature of the binder that used in ceramic injection molding which is Palm Stearin. TGA also has been conducted at the Instrumental Laboratory Faculty Chemical Engineering UITM Shah Alam as depicted in Figure 3. The parameter such as gas flow rate which is $50 \mathrm{ml} / \mathrm{min}$, heating temperature rate at $20^{\circ} \mathrm{C} / \mathrm{min}$ and maximum weight of the material that can use to get to proceed the TGA analysis is must not exceed $20 \mathrm{mg}$. The starting temperature before proceed TGA analysis is $25^{\circ} \mathrm{C}$ and will stop at the $550^{\circ} \mathrm{C}$. The figure 3 showed the TGA machine.

\subsection{Feedstock Preparation and Rheology Test}

There are two formulations that were used for this project which is 60\% (Alumina Zirconia) 40\% (Palm Stearin) and 64\%(Alumina Zirconia) 36\% (Palm Stearin). The composition of the powder and binder can be seen in the Table 1. In other to mix all the powder and binder altogether, the mass of material powders and binder need to be calculated. The machine used to mix the materials and binder was the speedmixer Dual Asymmetric Centrifuge (DAC) $600.1 \mathrm{FVZ}$. The rotation mixer is $800-1200 \mathrm{rpm}$ and were run until homogenous.

Table 1: show the Formulation of Alumina-Zircornia and Palm Stearin

\begin{tabular}{|c|c|c|c|}
\hline Formulation & $\begin{array}{c}\text { Alumina- } \\
\text { Zircornia (\%) }\end{array}$ & $\begin{array}{l}\text { Palm } \\
\text { Stearin(\%) }\end{array}$ & Total \% \\
\hline $\mathbf{1}$ & $60: 40$ & 40 & 100 \\
\hline $\mathbf{2}$ & $64: 36$ & 36 & 100 \\
\hline
\end{tabular}

Capillary rheometer was conducted to test the rheological behavior of the material. For CIM it must perform pseudoplastic behavior where the shear viscosity is decreased with the higher shear rate. In this process, the feedstock should be able to flow through the die in the capillary rheometer in order to achieve a successful result in the end of the test. The temperature of the capillary rheometer was set $50-60{ }^{\circ} \mathrm{C}$ as the melting temperature of the binder Palm Stearin is low as $55^{\circ} \mathrm{C}$. Previous study showed the relationship between viscosity and shear rate by the equation 1 as shown below.

$\eta=K \gamma^{n-1}$ 
Where the value of $\mathrm{K}$ is constant. The Activation Energy also can be defined as equation below:

$\eta=\eta_{0} \exp \left(\frac{E}{R T}\right)$

Where the value of $\eta_{0}$ is the viscosity at reference temperature. The value of $\mathrm{R}$ is constant, 8.314 and the value of $\mathrm{T}$ is the melting temperature.

\subsection{Injection Molding}

For the injection molding process, the temperature was set slightly above from melting point of Palm Stearin and wait for the temperature became constant. It is to ensure the temperature is sufficient for feedstock to flow through the gate and cavity. Then the feedstock was filled with $3 / 4$ volume into the chamber with pressure and heat applied to the feedstock. From the previous research, the temperature applied while using the injection molding machine usually $140^{\circ} \mathrm{C}-160^{\circ} \mathrm{C}$ but in this project, the temperature used is only $55^{\circ} \mathrm{C}$. This is because the melting point of the Palm Stearin is low compares to the others binder's melting point.

\subsection{Thermal Debinding and Pre-Sintering}

The thermal debinding and pre-sintered was begun in a one cycle step. The temperature of the thermal debinding process will go up to $550^{\circ} \mathrm{C}$ and the heating rate of the process is $0.5^{\circ} \mathrm{C} / \mathrm{min}$. Then the temperature will rise up until $700^{\circ} \mathrm{C}$ with the same heating rate which is $0.5^{\circ} \mathrm{C} / \mathrm{min}$ as for pre-sintering process.

\subsection{Sintering}

Mold sample were sintered at the different temperature to test the mechanical properties of the mold sample which is $1400^{\circ} \mathrm{C}$ and $1600{ }^{\circ} \mathrm{C}$. The sintering process is the process that strengthen the mold sample at high temperature as the mold sample were sintered at the temperature $3^{\circ} \mathrm{C} / \mathrm{min}$ for both $1400^{\circ} \mathrm{C}$ and $1600^{\circ} \mathrm{C}$.

\subsection{Mechanical Testing}

Hardness test was tested at the Material Science Laboratory Faculty Mechanical Engineering. The machine used for measuring the hardness test is Rockwell hardness test and the scale for the Rockwell hardness test is HRR scale. Each sample will indent about 3 times to get the average of the hardness.

\section{Result and Discussion}

\subsection{Sample Characterization}

The Scanning Electron Microscopic (SEM) test has been done to determine the characterization of the alumina powder and the zirconia powder. The Zirconia powder showed a good characterization as the size of the powder follow the criteria and give a good rheological behavior. Typical particle sizes in CIM are 1-2 $\mu \mathrm{m}$, but much finer particles down to submicron or nano region are being used in advanced CIM [3, 7]. As depicted in Figure 3a, the zirconia powder size is comparable for powder injection moulding used. The powder of the Alumina showed that the particle has a big size of powder that will affect the rheological properties of the material and the injection molding process as depicted in Figure $3 \mathrm{~b}$. The alumina powder provided in laboratory were performed milling process in order to reduce the size of particle to be used in CIM process as depicted in Figure $3 \mathrm{c}$. The size produce after milling process was below than $10 \mu \mathrm{m}$ and it was comparable with CIM requirement and then was successfully produce the green part.

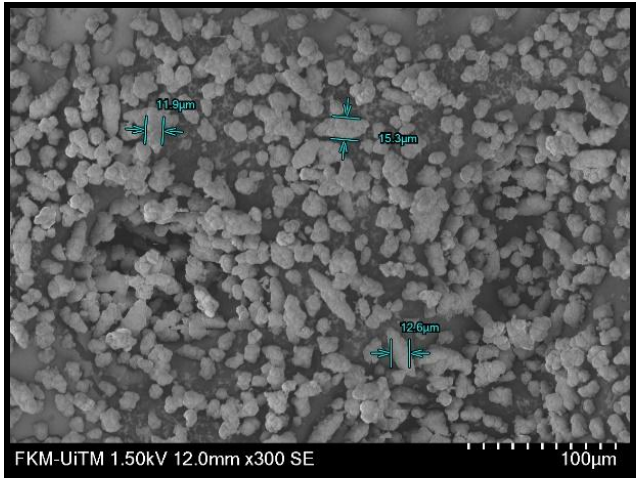

3a) Zirconia powder with size range $8-15 \mu \mathrm{m}$

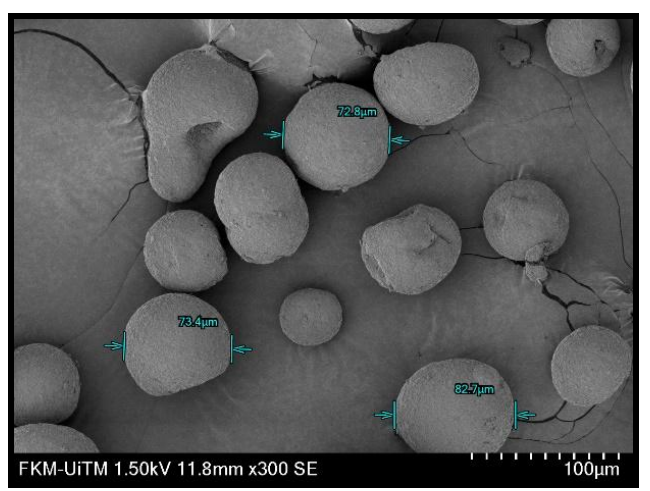

3b) Alumina powder with size range $70-150 \mu \mathrm{m}$

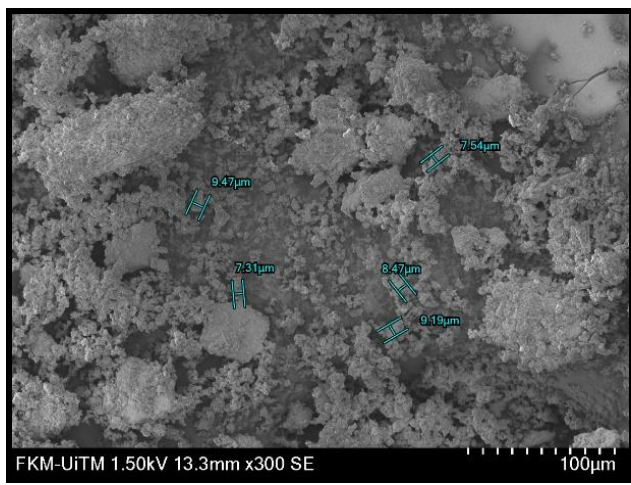

3c) Alumina Powder After using Ball Milling

\subsection{Pycnometer Density, TGA and DSC Binder Analysis}

The materials were analyzed its properties in order to proceed and calculating the formulation of the feedstock and also for thermal debinding process. The pycnometer density was used to determine its density of the material for each of the component. The Table 2 showed the density after using pycnometer density machine.

Table 2: Density of the Materials

\begin{tabular}{|c|c|}
\hline Material & Average Density $\left(g / \mathrm{cm}^{2}\right)$ \\
\hline Alumina & 3.6730 \\
\hline Zirconia & 5.6627 \\
\hline Palm Stearin & 1.0027 \\
\hline
\end{tabular}

TGA and DSC Analysis also were determined in order to determine the suitable temperature that will be used in mixing, rheological test and injection molding process. From the result that has been conducted showed that the binder used which is Palm Stearin fully decomposed is at $358.01^{\circ} \mathrm{C}$. DSC machine used to define the melting point of the binder and the result showed that the melting point of the Palm Stearin is $53^{\circ} \mathrm{C}$. The mixing and injection molding temperature was set based on the DSC result which is slightly higher at $55-60^{\circ} \mathrm{C}$ to allow the sufficient temperature to melt the binder. 


\subsection{Rheological Behavior}

Figure 3 show that formulation of $\left(64 \% \mathrm{Al}_{2} \mathrm{O}_{3}-\mathrm{Zr}+36 \% \mathrm{PS}\right)$ and $\left(60 \% \mathrm{Al}_{2} \mathrm{O}_{3}-\mathrm{Zr}+40 \% \mathrm{PS}\right)$ was comparable and exhibit psedoplastic behavior where the shear viscosity obtained was below than $200 \mathrm{~Pa} . \mathrm{s}$ at very low temperature of $50-60^{\circ} \mathrm{C}$. The good pseudoplastic behavior must permit the viscosity in the range of $10-1,000 \mathrm{~Pa}$. $\mathrm{s}$ and shear rate need to be in range $100-10,000$ $1 / \mathrm{s}$.

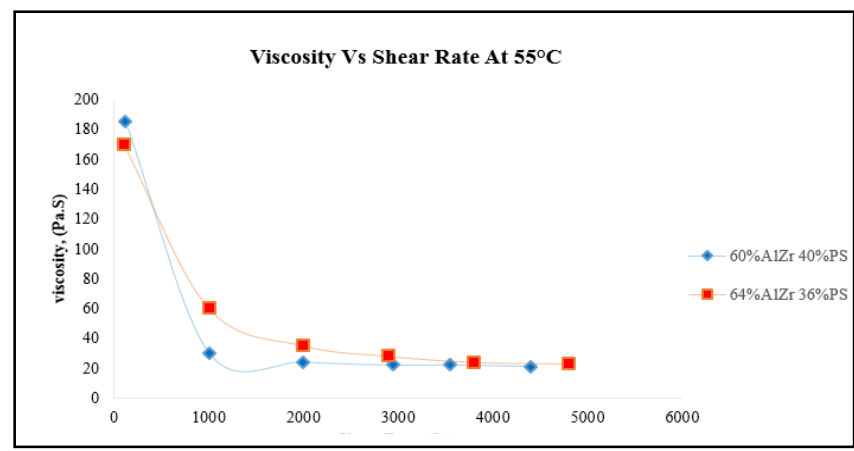

Figure 3: Graph Viscosity Against Shear Rate

Rheological properties are some of the important aspects in determining flowability of the feedstock as a function of shear rate and temperature. The flowability of the feedstock depends on the steady flow and the uniform filling into the mould cavity and subsequently provides important data for the next injection moulding process. The mixture needs to exhibit pseudoplastic behaviour where the viscosity degrades with the rise of shear rate. So it provides data such as the optimum required temperature and pressure to be used for the successful injection moulding process. Temperature used was around plays an important role. If sufficiently high, it will fully melt the binder and provide fluidity to form the desired shape.

Furthermore, Hausnerova et al. [8] reported the rheological behavior of aluminium oxide powder with multicomponent partly water-soluble polymeric binder (Licomont binder) to produce the defect free and non-porous parts. They found that the formulation of 60 vol.\% alumina powder with Licoment binder and the surfactant (1 wt. \% oleic acid) produce the pseudoplastic behaviour. The shear viscosity obtained was below $1000 \mathrm{~Pa}$.s with increasing of shear rate and the temperatures used for rheology test was 150,160 and $170{ }^{\circ} \mathrm{C}$.

\subsection{The Activation Energy, E}

From the previous study, the feedstock is highly sensitive to the temperature fluctuations during injection molding when the activation energy, $\mathrm{E}$ is high. As a result, the high activation energy gives a negative feedback because the probability it made the mold sample cracks is high and there is possibility that the feedstock will melt quickly in the mold and affect the structure of the molded part such as a hole and another defect.

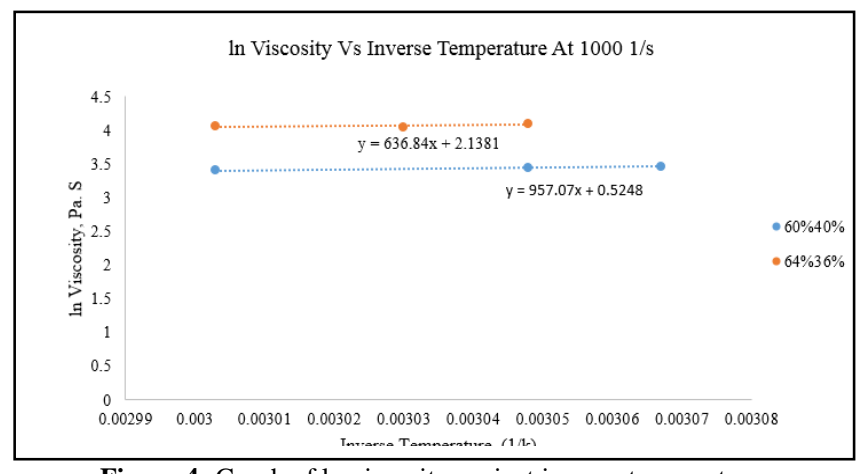

Figure 4: Graph of ln viscosity against inverse temperature
The graph in Figure 4 showed the ln viscosity against the inverse temperature at $1000 \mathrm{1} / \mathrm{s}$ where it is one of the step to find the value of the activation energy in order to see is it the formulation inhibits high activation energy or either way. From the figure above, the activation energy can be find where the slope of the graph which is the gradient is equal to $(\mathrm{E} / \mathrm{R})$, where $\mathrm{R}$ is a gas constant $(\mathrm{R}=8.314 \mathrm{~J} / \mathrm{mol} . \mathrm{k})$ and the result from the calculation to find the activation energy is shown as in table 3 .

Table 3: The flow behavior index and activation energy for both formulations

\begin{tabular}{|c|c|c|}
\hline Feedstock & $\begin{array}{c}\text { 60\%AluminaZirconia } \\
\text { 40\%Palm Stearin }\end{array}$ & $\begin{array}{c}\text { 64\%AluminaZirconia } \\
36 \% \text { Palm Stearin }\end{array}$ \\
\hline $\begin{array}{c}\text { Flow Behavior } \\
\text { Index, } n \\
\left(\text { At 5 5 }{ }^{\circ} \mathrm{C}\right)\end{array}$ & 0.94 & 0.828 \\
\hline $\begin{array}{c}\text { Activation } \\
\text { Energy, E } \\
(\mathrm{KJ} / \mathrm{mol} . \mathrm{K})\end{array}$ & 7.95 & 5.29 \\
\hline
\end{tabular}

Ultimately, for a productive injection moulding process with alumina feedstock, a crucial aspect is the temperature applied, which must definitely be below $70^{\circ} \mathrm{C}$ in order to get a better moulded specimen. The viscosity of the powder-binder mixture is the key feature since it is very sensitive to temperature.

It has been proven that at low temperature, the mixture viscosity may be too high for moulding. While at high temperature, the binder may be too thin, resulting in a powder-binder separation during moulding. This study is supported by German [9] who claimed that during injection moulding, cracking may be observed if the binder gradually drops with substantial thermal stress in the moulded specimens.

\subsection{Injection Molding Process}

Based on the rheological data obtained, the appropriate viscosity can be attained from the selected formulation of alumina feedstock leading to a successful injection moulding process. The good flowability properties exhibited from rheology analysis gave clear evidence of the quality of the moulded parts.

The injection moulding process can be executed very effortlessly since the injection moulding machine is quite simple and uncomplicated for handling. In order to generate uniform molecular orientation throughout the part, it is recommended to maintain a constant velocity at the melt front.

From scrutiny of rheological results, the injection moulding process was continued for 2 formulations of $\left(64 \% \mathrm{Al}_{2} \mathrm{O}_{3}-\mathrm{Zr}+36 \% \mathrm{PS}\right)$ and $\left(60 \% \mathrm{Al}_{2} \mathrm{O}_{3}-\mathrm{Zr}+40 \% \mathrm{PS}\right)$. These two formulations were chosen in order to see the correlation between powder loadings and at the same time the other powder loadings exhibited the same trend during mixing and rheology tests. The injection moulding process was performed at a moulding temperature of $70^{\circ} \mathrm{C}$ with the injection pressure applied in the range of $300 \mathrm{kPa}$ to $400 \mathrm{k} \mathrm{Pa}$. The green body which was successfully produced was free from any defects as depicted in Figure 5.

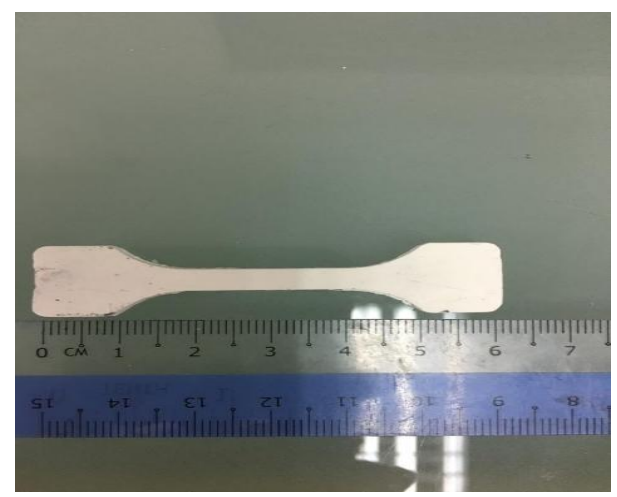

Figure 5: Mold sample after Injection 
One of the reason the mold sample being crack as in Figure 6 for the injection molding process is possibly due to the high value of the activation energy. This is because a high activation energy, E lead to the sensitivity of the feedstock towards the temperature. The formulation of the feedstock $\left(60 \% \mathrm{Al}_{2} \mathrm{O}_{3}-\mathrm{Zr}+40 \% \mathrm{PS}\right)$ has higher $\mathrm{E}$ than the other formulation that lead it to more hard to get a successful mold without cracks. Other than that, the rheological behavior of the formulation $\left(60 \% \mathrm{Al}_{2} \mathrm{O}_{3}-\mathrm{Zr}+40 \% \mathrm{PS}\right)$ also not a good pseudoplastic as $\left(64 \% \mathrm{Al}_{2} \mathrm{O}_{3}-\mathrm{Zr}+36 \% \mathrm{PS}\right)$ that make it mostly crack after injection molding.

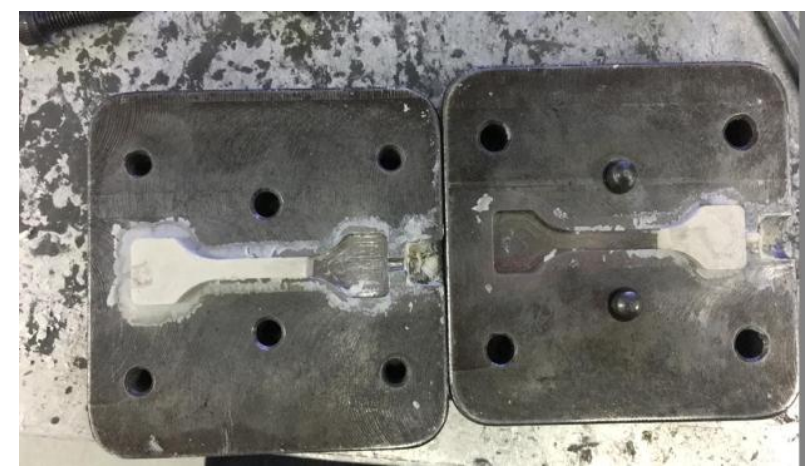

Figure 6: Crack occur after injection molding

\subsection{Thermal Debinding and Sintering Process}

Alumina wicking powder was used to avoid the mold sample from having any defect or cracks at any part of the mold during the thermal debinding process. Thermal debinding was running at the temperature $550{ }^{\circ} \mathrm{C}$ and hold for 3 hours then continued with the heating up to $700{ }^{\circ} \mathrm{C}$ at the $0.5{ }^{\circ} \mathrm{C} / \mathrm{min}$ in order to remove the binder palm stearin from the mold sample.

A slow heating rate was applied based on Gorjan [10] who reported that the successful debinding process is commonly achieved by applying a very low heating rate. As a result, the binder decomposed gradually and the removed binder was eradicated and extracted to the surrounding embedment of alumina powder through the capillary forces. During the thermal debinding stage, the formation of pores grew and subsequently strong adhesion between the adjacent particles began to develop, causing the retraction of the product in which it dimensions are usually reduced between $14 \%$ to $20 \%$ [11]. The next stage is the sintering process where the process was heated under the different temperature which is $1400{ }^{\circ} \mathrm{C}$ and $1600{ }^{\circ} \mathrm{C}$. The heating rate temperature used was $3{ }^{\circ} \mathrm{C} /$ min until it reached its temperature of sintering.

\subsection{Mechanical Testing}

The mechanical properties of the sintered sample, the hardness test was conducted at the Material Science Laboratory and being more specific of the test, Rockwell hardness test was carried. From Figure 8 it show that both formulation exhibit high hardness where the sintering temperature was directly proportional to the hardness value. Result show that the HRR value was about 100-120 HRR for sintering temperature at $1600^{\circ} \mathrm{C}$ and $85-90 \mathrm{HRR}$ for $1400^{\circ} \mathrm{C}$ sintering temperature.

This is supported by Ani et al. [12] where they were studied on the ZTA (Zircornia toughened Alumina) of formulation (57\% Al2O3$\mathrm{Zr}+43 \% \mathrm{HDPE} / \mathrm{PW} / \mathrm{SA})$. They found that at sintering temperature of $1600^{\circ} \mathrm{C}$, the theoretical relative density reached $97.89 \%$, whereas the hardness values reached $1582.40 \mathrm{HV}$. When at sintering temperature of $1400^{\circ} \mathrm{C}$ the hardness value obtained was $1220 \mathrm{HV}$.

\subsection{Morphology via SEM}

The image of the sintered sample for both formulation was conducted via using Scanning Electron Microscopic (SEM). The re- sult showed that the formulation $60 \% 40 \%$ have a pores and cracked after the mechanical testing were conducted. The other formulation which is $64 \% 36 \%$ showed less pores and have a good surface with a less crack at the temperature $1600{ }^{\circ} \mathrm{C}$. Table 4 depicted the SEM micrograph of sintered sample of 2 formulation of $60 \%$ alumina and $40 \%$ zircornia and second formulation of $64 \%$ Alumina with $36 \%$ zircornia. It shows that for $1400^{\circ} \mathrm{C}$ sintered temperature, the particle is start to diffuse and bond the particle together. While the $1600^{\circ} \mathrm{C}$ sintered temperature depicted the alumina and zircornia particle bonding is more strengthen and enhance properties of ZTA.

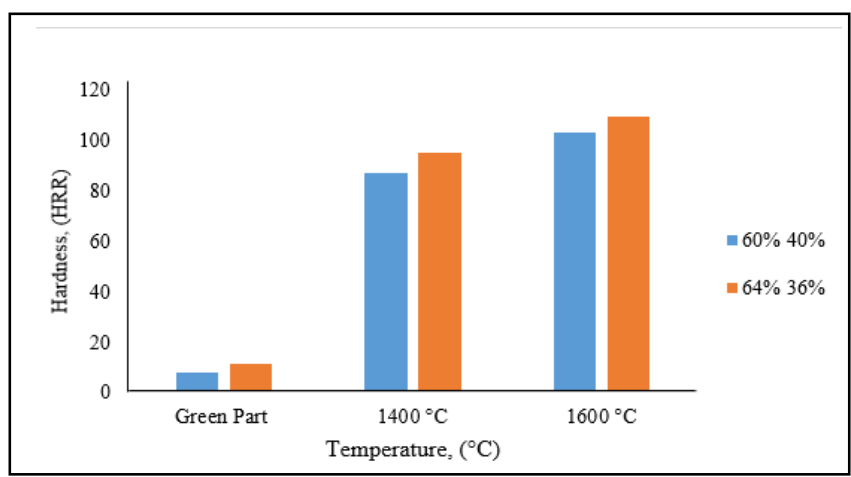

Figure 8: effect of the sintering on the hardness test

Table 4: depicted the SEM micrograph of sintered 2 formulation of $60 \%$ Alumina \& $64 \%$ alumina

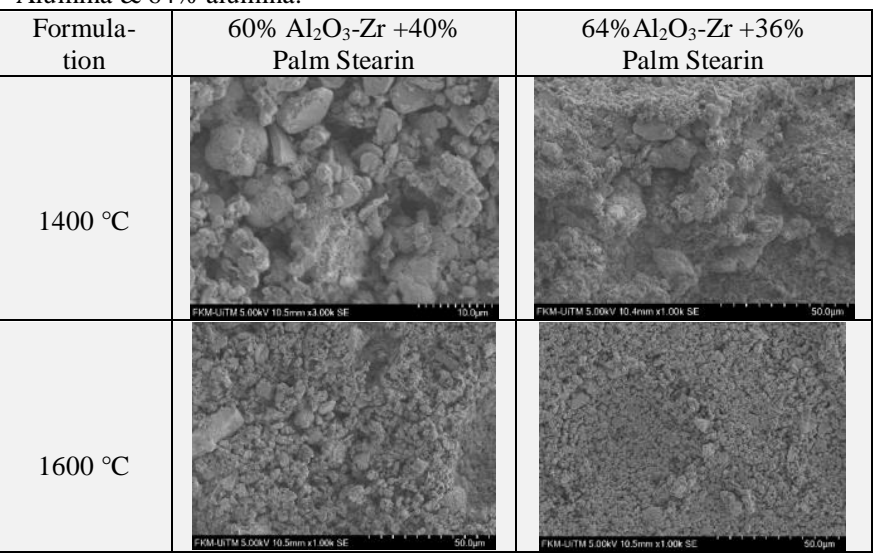

\section{Conclusion and Recommendations}

The both formulation of the feedstock $\left(64 \% \mathrm{Al}_{2} \mathrm{O}_{3}-\mathrm{Zr}+36 \% \mathrm{PS}\right)$ and $\left(60 \% \mathrm{Al}_{2} \mathrm{O}_{3}-\mathrm{Zr}+40 \% \mathrm{PS}\right)$ showed the comparable study where effect of additional material of zircornia improve the properties of alumina-zircornia injection molding. The alumina-zircornia (ZTA) was successfully fabricated through powder injection molding by using $100 \%$ single based binder of palm stearin by using speed mixer with dual assymetric centrifuge. It shows that even though just using a single binder, it can successfully obtain the pseudo-plastic behavior for rheology test and the processing temperature was used below than $70^{\circ} \mathrm{C}$. This can be a great concern for industrial production which can promote green technology and can lower the energy consumption.

\section{Acknowledgement}

The author would like to acknowledge the Material Science Laboratory, Composite Laboratory and Heat Treatment Laboratory Faculty of Mechanical Engineering, FKM at Universiti Teknologi MARA (UiTM), Shah Alam in conducting this study. 


\section{References}

[1] El-Ghany, O. S. A., \& Sherief, A. H. (2016). Zirconia based ceramics, some clinical and biological aspects. Future Dental Journal, 2(2), 55-64

[2] Malya, M., Rao, B., Sajjan, S., \& AV, R. R. (2017). An Overview on Zirconia.Trends in Prosthodontics and Dental Implantology, 6(2), 32-39.

[3] Stanimirović, Z., \& Stanimirović, I. (2012). Ceramic Injection Molding. In Some Critical Issues for Injection Molding. InTech.

[4] Mimi Azlina Abu Bakar, Siti Norazlini Abd Aziz, Muhammad Hussain Ismail, (2017) "Tribology study of hydroxyapatite (HAp) scaffold blended single based binder via rheology and mechanical properties", Industrial Lubrication and Tribology, Vol. 69 Issue: 3 , pp.414-419

[5] Ramli, M. I., Sulong, A. B., Arifin, A., Muchtar, A., \& Muhamad, N. (2012). Powder injection molding of SS316L/HA composite: rheological properties and mechanical properties of the green part. Journal of Applied Sciences Research, 8(11), 5317-5321.

[6] Aziz, A., Norazlini, S., Ali, N. H. M., Bakar, A., Azlina, M., Subuki, I., \& Ismail, M. H. (2016). The Influence of Single Based Binder of Palm Stearin in HAP Feedstock on Rheological Properties Used for Ceramic Injection Moulding (CIM). In Advanced Materials Research (Vol. 1134, pp. 220-224). Trans Tech Publications.

[7] Mannschatz, A., \& Moritz, T. (2009). Challenges in TwoComponent Ceramic Injection Moulding, Ceramic Forum International 86(4), pp 25-28.

[8] Hausnerová, B., Marcaníková, L., Filip, P., \& Sáha, P. (2011). Rheological characterization of powder injection moulding using feedstock based on aluminium oxide and multicomponent watersoluble polymer binder. Proceedings of Recent Advances in Fluid Mechanics and Heat \& Mass Transfer, 245-250.

[9] German, R. M., \& Bose, A. (1997). Injection Moulding of Metals and Ceramics. New Jersey. Metal Powder Industries Federations. (MPIF)

[10] Gorjan, L. (2012). Wick Debinding - An Effective Way of Solving Problems in the Debinding Process of Powder Injection Molding, Dr. Jian Wang (Ed.)

[11] Tandon, R. (2008). Metal injection moulding. In Encyclopedia of Materials: Science and Technology, Buschow, K. H. J., Cahn, R. W., Flemings, M. C., Ilscher, B., Kramer, E. J., Mahajan, S. \& Veyssiere, P. (Ed.), Elsevier Science Ltd, pp. 5439-5442.

[12] Ani, S. M., Muchtar, A., Muhamad, N., \& Ghani, J. A. (2014). Fabrication of zirconia-toughened alumina parts by powder injection molding process: Optimized processing parameters. Ceramics International, 40(1), 273-280. 